\title{
Consideraciones en torno al establecimiento de un régimen tributario común para las entidades de la economía social ${ }^{1}$
}

\author{
Marco Antonio Rodrigo Ruiz ${ }^{2}$
}

Recibido: 13 de marzo de 2017 / Aceptado: 16 de junio de 2017

Resumen. Las normas que regulan la tributación de las entidades pertenecientes a la Economía social se hallan dispersas en diferentes textos legales, aprobados en ocasiones en fechas muy alejadas y distantes. La fragmentación y dispersión de la regulación vigente hace que el tratamiento fiscal dispensado a cada uno de los diversos tipos de entidades de la economía social no responda a criterios comunes. Al contrario, esos regímenes fiscales singulares difieren ampliamente en buena parte de los casos, y, lo que es todavía más grave, se encuentran presididos por criterios que en ocasiones resultan ser abiertamente incompatibles y contradictorios entre sí. La Ley de Economía Social, a juicio del autor, concede nuevos y sólidos argumentos para corregir esas graves deficiencias de la regulación tributaria vigente y establecer un nuevo tratamiento fiscal, homogéneo y armónico, que alcance a toda clase de entidades integradas en el ámbito de la Economía Social.

Palabras clave: Tributación; Bonificaciones fiscales; Impuesto de Sociedades; Economía social; Cooperativas; Sociedades laborales; Mutuas; Entidades de previsión social; Asociaciones; Fundaciones; Centros especiales de empleo; Empresas de inserción social.

Claves Econlit: E62; H20; H29; H39; K00; K34; K40; L31; P13.

\section{[en] Considerations on the establishment of a common tax regime for social economic entities}

Abstract. The norms that regulate the taxation of the entities belonging to the Social Economy are dispersed in different legal texts, sometimes approved at very distant and distant dates. The fragmentation and dispersion of the current regulation means that the tax treatment provided to each of the various types of entities of the social economy does not respond to common criteria. On the contrary, these single tax regimes differ widely in most cases, and, even more seriously, they are governed by criteria that sometimes prove to be openly incompatible and contradictory to each other. The Social Economy Law, in the opinion of the author, grants new and solid arguments to correct these serious deficiencies of the current tax regulation and establish a new tax treatment, homogeneous and harmonic, that reaches all kinds of entities integrated in the field of Social economy.

Keywords: Taxation; Tax rebates; Corporation tax; Social economy; Cooperatives; Labor societies; Mutual societies; Social welfare entities; Associations; Foundations; Special employment centers; Social inclusion companies.

1 El presente estudio, aunque inédito, fue entregado al Instituto de Estudios Fiscales en noviembre de 2015, y para su actual publicación únicamente se han realizado en su contenido inicial las imprescindibles adaptaciones de orden legislativo que las modificaciones surgidas en dicho ámbito desde aquella fecha requerían.

2 Universidad del País Vasco, España

Dirección de correo electrónico: marcoantonio.rodrigo@ehu.eus 
Sumario. 1. Introducción. Incidencia en el ámbito tributario de la Ley de Economía Social 5/2011. 2. Principales notas distintivas de la tributación de las entidades de la Economía Social en la legislación vigente. 3. Propuestas de reforma. Especial referencia al establecimiento en el impuesto de Sociedades de un tipo bonificado común aplicable a la mayoría de las entidades de la economía social. 4. Conclusiones. 5. Referencias bibliográficas.

Cómo citar: Rodrigo Ruiz, M.A. (2017) Consideraciones en torno al establecimiento de un régimen tributario común para las entidades de la economía social. REVESCO. Revista de Estudios Cooperativos, No 125, pp. 187-212. DOI: 10.5209/REVE.57064.

\section{Introducción. Incidencia en el ámbito tributario de la Ley de Economía Social 5/2011}

La Ley de Economía Social 5/2011, de 29 de marzo, ha supuesto el espaldarazo definitivo al sector de la economía social por parte del legislador y del ordenamiento jurídico en su conjunto. Como dice el propio preámbulo de dicho texto legal, "el objetivo básico de la Ley es configurar un marco jurídico que... suponga el reconocimiento y mejor visibilidad de la economía social", de manera que la ley admite y otorga carta de naturaleza a una realidad económica y social con rasgos distintivos comunes o unitarios que permiten identificarla, diferenciándola a su vez de aquellas otras experiencias o prácticas económicas que no pertenecen al ámbito de la economía social ${ }^{3}$. En conexión con dicho propósito el artículo 1 de la ley establece que "la presente Ley tiene por objeto establecer un marco jurídico común para el conjunto de entidades que integran la economía social", aunque el precepto, en evitación de incertidumbres y vacíos normativos, expresa a su vez "pleno respeto a la normativa específica aplicable a cada una de ellas".

Ciertamente, la Ley de Economía Social, pese a significar sin duda un relevante hito, largamente ansiado por el sector, ha terminado resultando un cuerpo normativo de reducida extensión y alcance directo limitado, por cuanto da tratamiento a unas pocas materias específicas, más allá de configurar y definir legalmente a la economía social y establecer criterios para concretar las entidades que se integran en su ámbito. Por otro lado, el texto legal ha recibido solventes y razonados reparos doctrinales en lo que concierne a la configuración y delimitación de la económica social, y también en cuanto a su escueto contenido restante (se han expresado en sentido crítico Fajardo García, 2011; Paniagua Zurera, 2011; y Paz Canalejo, 2012).

No obstante, la mayor debilidad que a día de hoy ofrece la ley proviene de causas exógenas, y estriba en el flagrante e inaceptable incumplimiento de sus prescripciones por parte de los poderes públicos a los que el propio texto encomienda su aplicación y desarrollo (en este sentido, Pérez de Uralde, 2012; y 2014). No se trata de un asunto en absoluto menor, sino que, por el contrario,

\footnotetext{
El impacto o la trascendencia que para el reconocimiento institucional de un fenómeno social o económico tiene su reconocimiento normativo y su regulación legal ha sido expresado por Chaves, R.; Monzón, J.L.; Pérez de Uralde, J.M. y Radrigan, M. (2013, pág. 136), para quienes "la forma canónica de cristalizar el reconocimiento institucional de una realidad socioeconómica es a través de su consideración en la normativa, recogiéndola en las políticas generales y específicas, estableciendo órganos públicos especializados dedicados a esa realidad económica y sobre todo aprobando leyes que la regulan".
} 
resulta a mi juicio digno del máximo reproche, pues no hay nada más devastador, ni existe mayor erosión al Estado de Derecho preconizado por el artículo 1 de la Constitución, que el hecho de que los propios poderes públicos ignoren y desprecien la ley e incumplan de manera consciente, contumaz y sin paliativos los mandatos y obligaciones que en ésta se imponen. La lamentable extensión de esta reprobable costumbre, por desgracia cada vez más generalizada, priva de toda legitimidad al Gobierno y demás poderes públicos concernidos para exigir después a terceros el respeto y cumplimiento de cualesquiera otros textos legales, convirtiendo el uso de los medios coercitivos del Estado y de las normas sancionadoras en una mera exhibición de fuerza que no encuentran ya apoyo únicamente en la ley, sino en una decisión previa puramente arbitraria que determina los textos legales que han de ser cumplidos -y su incumplimiento corregido- y cuáles no. No cabe mayor agravio al Estado de Derecho que esta inadmisible práctica.

Con todo, y en la confianza (quizá ingenua) de que los poderes públicos afectados cumplan en el futuro la ley y reparen así el orden legal tan gravemente quebrantado, considero que, pese a las deficiencias y limitaciones que puedan ser achacadas a la ley $5 / 2011$, ésta ofrece una excelente oportunidad, que no debiera ser desdeñada ni desaprovechada, de repensar y someter a debate el régimen fiscal que a día de hoy tienen las diversas clases de entidades que forman parte de la economía social. Es verdad que, como ya se ha apuntado, su artículo 1 declara pleno respeto a la normativa específica aplicable a cada uno de los bloques o tipos de entidades componentes de la economía social, de modo que el tratamiento tributario por el que cada modalidad se rige mantiene plena vigencia. No es menos cierto, a su vez, que ya en el proyecto de ley remitido a las Cortes se eliminó toda referencia, entre las medidas de fomento que han terminado cristalizado en el vigente artículo 8 del texto legal, al establecimiento de exenciones, bonificaciones o deducciones tributarias (y también en las cotizaciones a la Seguridad Social), pese a que tales medidas estaban incluidas de forma explícita en el Informe para la elaboración de una Ley de fomento de la Economía Social elaborado para el Ministerio de Trabajo por un grupo de expertos (Monzón Campos, Coord.; Calvo Ortega; Chaves Avila; Fajardo García; Valdes Dal-Re, 2009); en concreto en el artículo 10.2, apartados c) y d), del texto articulado propuesto en dicho informe ${ }^{4}$-, de manera que cabe presuponer que la vertiente fiscal no ha querido incluirse en la Ley y resulta ajena a su ámbito. En este sentido, algún autor ha concluido que " $n i$ la LES contribuye a justificar un régimen tributario especial común a todas las entidades de la Economía Social, ni esto es siquiera imaginable" (Montesinos Oltra, S., 2012, pág. 30) $)^{5}$.

4 Ese artículo 10.2 del texto propuesto en el Informe señalaba que las políticas de fomento a desarrollar por los poderes públicos debían materializarse en medidas dirigidas a:

c) Establecer exenciones, reducciones o bonificaciones en las cotizaciones a la Seguridad Social.

d) Establecer exenciones, reducciones o bonificaciones tributarias.

5 El propio autor, no obstante, matiza líneas después su posición y sostiene que estaría justificada "la adopción de un régimen común de incentivos fiscales a la creación, capitalización y mantenimiento de entidades de la Economía Social, pero no, desde luego, el establecimiento de un régimen tributario especial común para el gravamen de su renta, que resulta inimaginable ante la variopinta realidad que presenta la Economía Social tal y como la delimita la LES" (Montesinos, 2012: 32). 
Aun respetando tales opiniones, entiendo, no obstante, que ha de ser convenientemente explorada la posibilidad de que la Ley de Economía Social se convierta en un factor que apoye el replanteamiento del régimen fiscal de las distintas entidades que componen dicha realidad socio-económica, al objeto, si no de unificar por completo las diversas regulaciones ahora existentes, al menos de aproximarlas y eliminar todas aquellas diferencias que carezcan de justificación bastante, pues la Ley 5/2011 ofrece vías en dicho sentido. Así, la Ley (artículo 1) declara tener por objeto el establecimiento de un "marco jurídico común", tarea que en modo alguno puede considerarse agotada con el parco contenido de la propia norma. Extremo que corrobora la disposición adicional séptima, que ordena al Gobierno aprobar "en el plazo de seis meses... un programa de impulso", entre cuyas medidas se encuentra (aptdo. $1^{\circ}$ ) la de revisar "la normativa necesaria para eliminar las limitaciones de las entidades de la economía social"6. Aunque no pueden desconocerse que esa supresión de limitaciones ha de tender en primer término, según explicita el precepto, a conseguir que los entes del sector "puedan operar en cualquier actividad económica sin trabas injustificadas", es indudable que a la remoción de trabas también puede contribuir el establecimiento de un régimen fiscal más acorde, no solo porque incorpore mayores incentivos fiscales, sino también por simplificar la regulación y facilitar el correcto cumplimiento de las obligaciones tributarias. En la misma línea, el artículo 8 de la Ley señala que las políticas de promoción y fomento de la economía social han de tener entre sus objetivos el de "remover los obstáculos que impidan el inicio y desarrollo de una actividad" -art. 8.2. a)- y el de "facilitar las diversas iniciativas de economía social" -art. 8.2. b)-, propósitos ambos para cuya consecución las medidas fiscales pueden jugar un destacado papel.

Además de las previsiones legislativas mencionadas, que permiten acudir al ordenamiento tributario para colmar las aspiraciones y planteamientos de la ley, considero que existe un factor aún más significativo y relevante para auspiciar un replanteamiento de los dispersos y distantes regímenes fiscales en vigor para cada uno de los tipos de entidades que forman parte de la economía social. En efecto, debe concedérsele la trascendencia que merece al hecho indiscutible de que una disposición de rango legislativo otorgue explícitamente carácter unitario a todas las entidades de la economía social y les reconozca, más allá de sus diferencias, por significativas que sean, rasgos comunes, entre los que se encuentran la observancia de principios coincidentes y la prosecución de objetivos afines (art. 4 de la ley), aspectos ambos que son los que justifican la promoción y el fomento del sector en su conjunto. La ley, en suma, adaptándose a la realidad, entroniza en nuestro ordenamiento y eleva a categoría jurídica a un fenómeno o segmento económico la economía social- que hasta entonces no había tenido un respaldo normativo directo y explicito tan elocuente. Esta identificación jurídica del sector, y la

6 Una vez más este mandato ha de considerarse, a día de hoy, abiertamente incumplido, pues no cabe entender en modo alguno que resulte colmado con el tardío y fantasmagórico Programa de Fomento e Impulso de la Economía Social 2015-2016 que, en el seno del Ministerio de Empleo y Seguridad Social, fue emitido con fecha 20 de julio de 2015 por la Dirección de Trabajo Autónomo, de la Economía Social y de la Responsabilidad Social de las Empresas, sin más publicidad que su inserción en la página web del Ministerio, y sin que el documento haya sido objeto de tramitación administrativa ulterior, ni, en consecuencia, el Gobierno se haya pronunciado sobre el mismo. 
plasmación de sus rasgos comunes, fuerza a plantear si existen razones bastantes para justificar la enorme dispersión y variedad de los regímenes fiscales que a día de hoy afectan a las distintas entidades que componen la economía social, o si, por el contrario, en ausencia de tales razones es necesario un acercamiento y simplificación de esos regímenes especiales. A analizar esta cuestión se dedicarán las siguientes líneas, partiendo para ello de un somero repaso a la situación presente y a sus principales rasgos característicos.

\section{Principales notas distintivas de la tributación de las entidades de la Economía Social en la legislación vigente}

Conviene advertir de inicio que no es propósito de este trabajo -sería una labor que rebasa con creces la extensión máxima asignada al mismo- analizar en detalle todos y cada uno de los regímenes fiscales especiales que afectan a los diversos entes que forman parte de la economía social, o ni siquiera hacer una breve referencia completa de los mismos. Dicho análisis previo va a limitarse, por tanto, a describir los principales rasgos generales que, en mi opinión, pueden atribuirse a esa pluralidad de regímenes tributarios existentes, a cuyo fin cabe aislar las cuatro características principales siguientes:

\subsection{Dispersión normativa}

La primera nota caracterizadora de la regulación tributaria aplicable a los diferentes tipos de entidades pertenecientes a la economía social es la dispersión de las disposiciones que establecen previsiones fiscales singulares o particulares para cada uno de dichos tipos diferenciados. Sin ánimo exhaustivo alguno, sino a título de mero ejemplo, cabe recordar la existencia, por un lado, de textos legales específicos dedicados a regular el régimen fiscal de alguno de estos entes, como sucede con la Ley 20/1990, de 19 de diciembre, referida a las cooperativas, o con la Ley 49/2002, de 23 de diciembre, que alcanza a las fundaciones y a las asociaciones declaradas de utilidad pública, siempre que cumplan con los requisitos establecidos en su artículo 3. Por otro lado, nos encontramos también con la presencia de cuerpos legislativos destinados a la ordenación general de otras figuras de la economía social en los que, dentro de esa regulación global, se insertan las particularidades tributarias de dichas figuras, tal como sucede con las sociedades laborales y su Ley 44/2015, de 14 de octubre (vid. su art. 17), que reduce a la mínima expresión los ya de por sí escasos beneficios fiscales establecidos en la Ley 4/1997, de 24 de marzo (arts. 19 y 20, y disp. transitoria tercera de la misma). Finalmente, son en otras ocasiones las disposiciones reguladoras del impuesto de Sociedades (o muy ocasionalmente de algún otro impuesto) las que recogen las particularidades tributarias de otros segmentos de la economía social, como es el caso del régimen especial de las sociedades parcialmente exentas, al que pueden acogerse (art. 109 de la Ley 27/2014, de 27 de noviembre) tanto las fundaciones y asociaciones sin ánimo de lucro a las que no les sea aplicable la ley 49/2002, como las uniones, federaciones y confederaciones de 
cooperativas, y también por último las mutuas colaboradoras de la Seguridad Social.

A esta dispersión formal, en lo que a la diversidad normativa concierne, cabe agregar otra dispersión de carácter temporal o cronológico, reveladora una vez más de que la normativa vigente pretendió en cada caso, con mayor o menor fortuna y amplitud, afrontar los problemas de cada sector y darles respuesta individualizada, pero que, en cambio, el legislador no ha abordado jamás la regulación tributaria de estos entes desde una visión global ni de conjunto, y tampoco ha tenido nunca en cuenta la común pertenencia de los mismos al ámbito de la economía social, ni los rasgos que a ésta le caracterizan e individualizan, perspectivas que han brillado siempre por su absoluta ausencia.

\subsection{Obsolescencia}

Más allá de las reglas especiales incluidas en el impuesto de Sociedades, que, obviamente, se renuevan o ratifican cada vez que se produce una reforma general del tributo, y cuya regulación vigente se encuentra en la reciente Ley 27/2014, de 27 de noviembre, buena parte de los regímenes tributarios singulares referidos a entes de la economía social proviene de textos legales cuyo origen, salvo alguna reforma reciente, como la acontecida con la Ley de Sociedades Laborales 44/2015, data de años remotos: 1990, en cuanto a las cooperativas; y 2002, en cuanto a las fundaciones y asociaciones de utilidad pública acogidas a la denominada ley de mecenazgo. Se trata de textos legales desfasados y obsoletos, que se encuentran, especialmente en el caso de las cooperativas, pero también en los restantes supuestos, superados por la abundante emanación posterior de nueva regulación: de un lado, legislación societaria o sustantiva (entre ella, tomando como ejemplo a las cooperativas, la vigente ley estatal sobre la materia, así como una gran pluralidad de leyes autonómicas, alguna de ellas, como la del País Vasco, sucesivamente reformada); de otro, normativa tributaria general de directa aplicación (basta, a efectos ilustrativos, mencionar el impuesto de Sociedades, amplia y reiteradamente reformado desde 1990 -Ley de 1995, TR de 2004, y reciente Ley de 2014, como modificaciones de mayor relevancia-).

\subsection{Heterogeneidad sustantiva}

A la diversidad formal y cronológica apuntadas se añade, como lógica consecuencia, el contenido manifiestamente dispar de las disposiciones tributarias arbitradas para cada tipo de entidad de la economía social objeto de tratamiento. Dicha heterogeneidad o diversidad material resulta muy acusada, hasta el punto de que, mientras las cooperativas o las fundaciones y asociaciones de utilidad pública que puedan acogerse a la ley 49/2002 disponen de una regulación detallada que incluye ventajas tributarias significativas (aunque comparativamente hayan ido perdiendo paulatinamente peso respecto a la normativa tributaria general), en cambio las sociedades laborales mantiene tan solo en su nueva ley una única 
bonificación en el impuesto de Transmisiones Patrimoniales (en adelante ITP) ${ }^{7}$, cuya escasa entidad impide siquiera, como ya había puesto de relieve la doctrina en base a la más favorable normativa precedente, hablar en puridad de régimen tributario especial para dicho entes (De la Peña Velasco, 1997). En el extremo inferior de esta escala de disparidad material de tratamiento tributario se encuentran las mutuas de seguros y las mutualidades de previsión social, que tras la nueva ley del impuesto de Sociedades 27/2014, de 27 de noviembre, se hallan, a partir de los periodos impositivos iniciados en el año 2016, huérfanas de cualquier incentivo fiscal específico, situación que, sobre todo respecto a las entidades de previsión social voluntaria, supone un escandaloso caso de injustificable discriminación negativa, no ya tan solo frente a otros entes de economía social, sino sobre todo, y muy especialmente, sobre su figura más afín: los planes y fondos de pensiones (aspecto éste al que me referiré en detalle más adelante).

\subsection{Regímenes fiscales con determinadas características comunes}

Aunque el tratamiento dispar y en absoluto coincidente que dispensan a las diferentes entidades de la economía social sus particulares regímenes fiscales se aprecia con toda nitidez a primera vista tras un examen, por somero y superficial que sea, de dichas disposiciones legales, no es menos cierto que cabe detectar algunos criterios rectores coincidentes, que permiten vislumbrar una cierta similitud o proximidad en el planteamiento general que orienta la mayor parte de estos regímenes singulares. Anticipo, antes de entrar en su descripción y examen, que en mi opinión los criterios básicos que presiden el establecimiento de tales normas tributarias especiales no son acertados ni correctos y causan importantes distorsiones, aun siendo plenamente consciente que este parecer no es compartido por algunos ilustres analistas de la materia, para los que la actual configuración es adecuada y cuenta con justificación suficiente (De Luis Esteban, 1985; Barberena Belzunce, 1992; y Montero Simó, 2001). Centraré la exposición en las que considero son las dos notas distintivas básicas comunes a estos regímenes fiscales.

\subsubsection{La fragmentación o bifurcación de la renta obtenida o de la base imponible, a fin de declarar la exención de una parte de los ingresos en el impuesto de Sociedades o de gravar cada fracción con distinto tipo de gravamen}

Pese a que algunas entidades de la economía social cuentan en sus regímenes tributarios especiales con otras medidas de protección fiscal, tanto en la imposición estatal indirecta (en particular en el ITP y AJD) y en la tributación local, como en el propio impuesto de Sociedades, donde se contempla la posibilidad de optar por la libertad de amortización, no ofrece duda alguna que el principal incentivo del

\footnotetext{
El artículo 17 de la vigente Ley 44/2015 únicamente contempla la bonificación del 99 por 100 de las cuotas de ITP, modalidad transmisiones onerosas, que se devenguen por la adquisición de bienes y derechos procedentes de la empresa de la que provengan la mayoría de los socios trabajadores. Se suprimen así las restantes bonificaciones y la exención previstas en el artículo 19 de la Ley 4/1997, lo que, huelga decirlo, lejos de cambiar el planteamiento preexistente, no hace más que reincidir en el mismo, asumiéndolo a la baja.
} 
que disponen a día de hoy la mayoría de tales entidades, a la vista de su extensión e impacto económico, es la exención o la tributación atenuada -mediante tipo reducido-, en el impuesto de Sociedades, de determinados ingresos obtenidos en sus actividades (raramente la exención resulta completa y alcanza a la totalidad de los beneficios, supuesto que solo puede darse, y no siempre, en las entidades sin fines lucrativos -fundaciones y asociaciones- acogidas a la ley 49/2002).

Pues bien, las exenciones y bonificaciones en el impuesto de Sociedades a las rentas obtenidas por las entidades de economía social tienen un punto de partida coincidente en todos los casos, que consiste en establecer distingos en atención al origen o procedencia de los ingresos, de manera que la exención, bonificación o tipo reducido de turno no alcanza a la totalidad de los beneficios obtenidos, sino solo a los ingresos que procedan de determinadas fuentes de renta -salvo en las fundaciones o asociaciones de utilidad pública acogidos en la ley 49/2002, en que la exención, como de inmediato se dirá, puede ser total-.

Profundizando más en este rasgo común, cabe agregar también que, dentro de este tratamiento diferenciado de los ingresos, por regla general los beneficios provenientes de cualquier actividad económica que realice la entidad quedan sometidas a gravamen en el impuesto de Sociedades, ya sea a tipo general, ya a diferentes tipos bonificados. Los tipos reducidos que actualmente subsisten son del 10 por 100 en el caso de las fundaciones y asociaciones acogidas a la ley 49/2002 aunque en tales entidades, por excepción, la mayor parte de las veces las actividades económicas que desarrollan se hallarán completamente exentas- ${ }^{8}, \mathrm{y}$ del 20 por 100 para los resultados cooperativos de las cooperativas fiscalmente protegidas $^{9}$. Por su parte, el tipo general ahora vigente del 25 por 100 se aplica a las sociedades laborales, y a las cooperativas respecto a las actividades $-\mathrm{y}$ resto de resultados- de naturaleza extracooperativa ${ }^{10}$. También conservan el tipo de 25 por 100 entidades que ya lo tenían previamente establecido antes de la aprobación de la Ley del impuesto 27/2014, situación en la que se encuentran las fundaciones y asociaciones a las que no resulta de aplicación la ley 49/2002, las mutuas de seguros, mutualidades de previsión social voluntaria, y mutuas colaboradoras de la Seguridad Social y por último las uniones, federaciones y confederaciones de cooperativas ${ }^{11}$, aunque para todos estos obligados tributarios el mantenimiento de dicha alícuota ha supuesto, a partir de los periodos impositivos que se inicien dentro del año 2016, la pérdida del tipo bonificado de que antes gozaban, toda vez que éste ha pasado a homologarse o identificarse con el que ahora es el general del

8 Aunque el art. 10 de la Ley 49/2002 (y también el art. 29.3 de la Ley 27/2014) fija el gravamen de las rentas derivadas de explotaciones económicas en el indicado tipo del 10 por 100, sin embargo, como acaba de apuntarse, existe aquí una importante excepción a la regla general de que las actividades económicas tributan siempre, dado que el artículo 7 de la Ley 49/2002 establece un listado de explotaciones económicas de estos entes que se declaran plenamente exentas del impuesto de Sociedades, relación en la que se comprenden todas las que sean desarrolladas en cumplimiento de su objeto o finalidad específica, las que tengan un carácter meramente auxiliar o complementario de las anteriores, y las que sean de escasa relevancia.

9 Art. 29.2 de la Ley 27/2014, del impuesto de Sociedades y 33.2.a) de la Ley 20/1990, de régimen fiscal de las cooperativas.

10 Art. 29.2 de la Ley 27/2014, del impuesto de Sociedades, y art. 33.2.b) de la Ley 20/1990, de régimen fiscal de las cooperativas.

11 Vid. art. 28.2 del anterior Texto refundido del impuesto, aprobado por el R. Decreto legislativo 4/2004, de 5 de marzo, y, en la actualidad, arts. 29.1, 9.3, 110.1, y disposición transitoria trigésimo cuarta, aptdo. i), reglas $1^{\mathrm{a}}, 5^{\mathrm{a}}$ y $7^{\mathrm{a}}$, de la Ley $27 / 2014$, del impuesto de Sociedades. 
tributo $^{12}$, de manera que estos entes de la economía social han perdido por el momento la ventaja fiscal de acogerse de forma ordinaria a un tipo reducido, efecto negativo que en buena medida resulta también extensible a la gran mayoría de las sociedades laborales ${ }^{13}$.

Este mayoritario y extendido criterio de someter a gravamen las rentas de las entidades de la economía social provenientes del desempeño de actividades económicas -que solo cuenta con la salvedad, a la que se ha hecho referencia en una anterior nota a pie de página (la núm. 10), de las fundaciones y asociaciones de utilidad pública a las que resulte de aplicación la ley 49/2002, para las cuales se establece la exención de las rentas derivadas de sus explotaciones económicas, en los términos que el artículo 7 de dicho texto legal señala-, se conjuga con una amplia exención para otras fuentes de renta, tanto en el caso de las fundaciones y asociaciones citadas de la Ley 49/2002 (art. 6 de la misma), como en el de las figuras de la economía social a las que resulta de aplicación el régimen de las entidades parcialmente exentas previsto en la regulación del impuesto de Sociedades -fundaciones y asociaciones sin ánimo de lucro ajenas a la Ley 49/2002, uniones, federaciones y confederaciones de cooperativas y mutuas colaboradoras de la Seguridad Social-, cuyo catálogo de rentas exentas es más reducido (art. 110 de la Ley 27/2014), mientras en el caso de las cooperativas fiscalmente protegidas el tratamiento legal expuesto da lugar a la configuración de dos niveles diferenciados de tributación, el correspondiente a los resultados cooperativos, gravados al tipo del 20 por 100 , y el de los resultados extracooperativos, para los que rige el tipo general del impuesto de Sociedades (art. 33.2 de la Ley 20/1990).

El panorama descrito, por otro lado más que sobradamente conocido, provoca en la mayor parte de figuras de la economía social la descomposición analítica de las rentas generadas por las citadas entidades y de los gastos inherentes a las mismas, bien para fragmentar y desdoblar la base imponible del impuesto, a fin de que cada clase de resultados, como ocurre en las cooperativas, tribute al tipo de gravamen que le pertenece, bien para excluir de la base imponible a las rentas -con sus gastos- declaradas exentas ${ }^{14}$.

Este régimen dual, amén de la elevada presión fiscal indirecta que genera, inasumible para muchas pequeñas entidades, y de las altas dosis de incertidumbre e inseguridad jurídica que asimismo conlleva -cuestiones ambas a las que luego me

12 El tipo general vigente del 25 por 100, establecido en el art. 25.1 de la Ley 27/2014, del impuesto de Sociedades, ha sustituido a los tipos generales precedentes, fijados en el 30 por 100 por el art. 28.1 del R. Decreto legislativo 4/2004 en su última redacción, y, durante el periodo de 2015, en el 28 por 100, según la disposición transitoria trigésimo cuarta, letra h), de la Ley 27/2014.

13 Repárese en que la inmensa mayoría de las sociedades laborales existentes, por reunir los requisitos para ser calificadas como entidades de reducida dimensión, han podido tributar al tipo, entonces bonificado, del 25 por 100 por la parte de base imponible que no rebasara la cantidad de 300.000 euros, o incluso por la totalidad de sus beneficios si cumplían determinados requisitos de mantenimiento de empleo -vid. art. 114 del R. Decreto legislativo 4/2004 y disposición transitoria trigésimo cuarta, aptdos. j) y k) de la Ley 27/2014, del impuesto de Sociedades-.

14 La situación no alcanza, sin embargo, a las sociedades laborales, que tributan en el impuesto de Sociedades sin particularidad relevante alguna, y tampoco afecta hoy a las mutuas de seguros generales ni a las mutualidades de previsión social, que, como ya se ha dicho, han perdido el tipo bonificado del que disponían, una vez que éste se ha identificado con el general del impuesto, y se han visto privadas de cualquier diferencia apreciable en su tratamiento fiscal. 
referiré- resulta a mi juicio inadecuado y abiertamente criticable. Sobre todo entiendo que es la objeción de mayor relevancia-, porque confunde y distorsiona los motivos por los que la protección fiscal ha de concederse, que en modo alguno se encuentran en el origen o fuente de las rentas, sino que ha de basarse en el destino o aplicación de los beneficios obtenidos.

En efecto, el destino de los beneficios permite arbitrar medidas de incentivación o bonificación fiscal, ya sea en atención a los fines sociales o de utilidad pública a los que la entidad dedica los excedentes obtenidos, ya tomando en consideración las previsiones legales y/o los pactos estatutarios que impiden o limitan el reparto de los beneficios entre los socios, miembros o participes de la entidad y lo afectan ineludiblemente a la cobertura del objeto o fin social, ya incluso en apoyo a criterios de reparto o distribución de los resultados de carácter mutual, basados en la actividad y esfuerzo del socio o partícipe y no en su mera aportación económica a la entidad.

En cambio, el origen o fuente de la renta es un factor que no justifica diferencias de tributación ni desde la capacidad económica o contributiva, principio de justicia rector por antonomasia del ordenamiento tributario plasmado en el artículo 31.1 de la Constitución, ni tampoco con base en la reconocida posibilidad de que el tributo sirva o se utilice como instrumento para la realización de los principios y fines contenidos en la Constitución (art. 2.1. de la LGT 58/2003), propósito que, obviamente, solo puede conseguirse en atención al uso o empleo que se haga del resultado, pero no con arreglo a su procedencia.

Así pues, no existen razones técnicas solventes que justifiquen que las bonificaciones a una entidad se arbitren en función del origen de sus beneficios, y, como ya sostuve antes de que la Ley 20/1990 fuese aprobada (Rodrigo Ruiz, 1989), tal discriminación supone un retroceso técnico considerable con respecto a los criterios que presidieron la modernización y reforma de nuestro sistema fiscal realizada en los años 1977 y 1978, porque transforma a un impuesto directo con vocación de generalidad como el de Sociedades en una simple adición de impuestos de producto que, al igual que los antiguos impuestos a cuenta, termina gravando de manera distinta e individualizada cada particular y especifica fuente de renta.

En cualquier caso, aunque, en contra del parecer expuesto, se juzgase correcto y conveniente seguir discriminando el gravamen de las rentas societarias en función de su origen, resulta harto discutible que el trato diferente deba conservar el signo que en la actualidad posee, según el cual las actividades económicas -con la excepción apuntada de la ley 49/2002- tributan siempre, mientras rendimientos y ganancias derivadas de otras fuentes son consideradas exentas o tributan en menor medida. Ciertamente, buena parte de las rentas exentas o bonificadas tienen su amparo en el principio mutual, en cuya defensa y fomento los ingresos que a las entidades realicen los socios, participes o miembros de las mismas son objeto de protección tributaria, pero no cabe ignorar que también otros rendimientos y ganancias del capital reciben este beneficioso tratamiento, dando lugar a que los resultados directos que genera el emprendimiento social tengan una fiscalidad más gravosa que las rentas, pasivas u ociosas, que derivan del capital o patrimonio preexistente. El emprendimiento, en suma, resulta de peor condición, a efectos tributarios, que otras fuentes de renta, lo que arroja un resultado abiertamente 
opuesto al discurso oficial sobre la materia (situación por lo demás plenamente extrapolable al IRPF, donde, huelga decirlo, las rentas derivadas del esfuerzo personal, por trabajo dependiente o por actividad económica autónoma, son peor tratadas que las rentas del ahorro, haciendo primar razones de mera oportunidad o pretendida -e indemostrada- eficiencia, que se anteponen y relegan, vulnerándolos, a los principios de justicia tributaria).

\subsubsection{El predominio del principio mutual como factor determinante de la protección fiscal a las entidades de económica social: mención a las injustificadas diferencias que conforme a dicho criterio se generan, con especial referencia a las mutualidades de previsión social}

Otra nota coincidente en los distintos regímenes tributarios especiales que afectan a entidades de la economía social es que las ventajas fiscales arbitradas giran prácticamente en su globalidad (de nuevo con la excepción, a la después se aludirá, de lo previsto en la Ley 49/2002) en torno al carácter mutual de tales entidades, y al mejor tratamiento impositivo que, en base al mismo, reciben las operaciones que la entidad realiza con sus socios, miembros o participes.

En efecto, los beneficios a las cooperativas se ciñen en lo sustancial a dicho criterio. Por un lado, los resultados cooperativos, aquellos que la entidad obtiene sobre todo en función de las actividades y operaciones que la sociedad realiza con sus socios, tributan en el impuesto de Sociedades al tipo reducido del 20 por 100, frente a los restantes resultados, los extracooperativos, gravados a tipo general. Por otro lado, la bonificación en la cuota para las cooperativas especialmente protegidas depende, en éstas, de que se mantenga un determinado porcentaje de operaciones o de nivel de actividad con los socios, esto es, de que se mantenga un elevado respeto al principio mutual (vid. arts. $8.3 ; 9.1$ y $2 ; 10.1,2$ y $3 ; 11.1$ y $3 ;$ y 12.1, 3 y 4 de la Ley 20/1990).

A su vez, las personas jurídicas a las que a lo largo del tiempo ha resultado aplicable el régimen especial de las entidades parcialmente exentas tienen su principal exención en "las cuotas satisfechas por los asociados, colaboradores o benefactores" (art. 110, a, de la Ley 27/2014) y en las adquisiciones a título lucrativo (art. 110, b), operaciones estas últimas que en buena medida suelen proceder también de sus miembros o de los sujetos que acaban de indicarse, con lo que la primacía del principio mutual parece también incuestionable.

No obstante, existen significativas entidades de la economía social en que la situación es diferente. En algún supuesto por exceso, como sucede con las fundaciones y asociaciones de utilidad pública de la ley 49/2002, pues al criterio mutual, que no desaparece, sino que también se encuentra presente en términos homólogos a lo que sucede con las entidades parcialmente exentas reguladas en la ley del impuesto de Sociedades, lo que da lugar a la exención de las aportaciones, cuotas y donativos de fundadores, asociados, y colaboradores - art. $6.1^{\mathrm{a}}$, aptdos a) y b) de la ley 49/2002-, se añade además un régimen fiscal más beneficioso, que declara exentos en el impuesto de Sociedades a otro amplio listado de ingresos (arts. 6 y 7 de la Ley 49/2002) y únicamente grava a tipo reducido del 10 por 100 las rentas derivadas de explotaciones económicas no exentas, que en condiciones ordinarias serán meramente residuales (arts. 8 y 10 de la Ley 49/2002). Estos 
amplios beneficios se hallan supeditados al cumplimiento de una serie de requisitos (art. 3 de la Ley 49/2002), entre los que cobra especial relevancia, en aras a justificar el establecimiento de dicho régimen fiscal, el relativo al destino que ha de darse a las rentas e ingresos, que han de dedicarse a la consecución de fines de interés general, así como la afectación total de su patrimonio, en caso de disolución, a la cobertura de dichos fines (aptdos. $1^{\circ}, 2^{\circ}$ y $6^{\circ}$ de dicho artículo 3 ).

De otro lado, hay también otros entes de la economía social que reciben un trato diferente, en este caso por defecto, en la medida que la observancia de criterios mutuales en su configuración y funcionamiento no les reporta, paradójica y contradictoriamente, ventaja tributaria alguna. En este grupo pueden alinearse las sociedades laborales $\mathrm{y}$, de modo harto sorprendente, según se dirá, las mutualidades de previsión social voluntaria. En cuanto a las sociedades laborales, la circunstancia de que la mayoría del capital social tenga que ser propiedad de trabajadores de la propia entidad con contrato laboral indefinido, y la intervención de otros trabajadores no socios por tiempo indefinido esté formalmente limitada (art. 1 de la Ley 44/2015), son extremos que no tienen el menor efecto incentivador o reductor en el impuesto de Sociedades, pese a su indudable consideración mutual.

Capítulo aparte merecen las mutuas de previsión social voluntaria, pues la situación fiscal en que se encuentran es todavía más llamativa y sorprendente. Dichas entidades, que gozaron de una exención total en el impuesto de Sociedades con el antiguo Texto Refundido de 23 de diciembre de 1967, han soportado después un tortuoso y conflictivo régimen de bonificación parcial, establecido en el artículo 5.2 de la Ley del impuesto 61/1978, que excluía de la exención y sometió a gravamen a los beneficios procedente de actividades económicas, y también a los incrementos patrimoniales y rendimientos derivados de la cesión del patrimonio (exclusiones ambas que privaron prácticamente de significado a la exención en esta clase de entes ${ }^{15}$ ), hasta que la Ley de mecenazgo 30/1994, en su disposición adicional novena, excluyó a las mutualidades de previsión social de la referida exención parcial, en decisión ratificada poco después por la Ley del impuesto de Sociedades 43/1995 (no deja de resultar paradójico, pese a que la exención tuviera ya casi nula relevancia, que fuese un texto legal acuñado para el fomento de la participación privada en actividades de interés general el que eliminase definitivamente la exención a las mutualidades). Tras dicha supresión, las mutuas de previsión han tributado por la totalidad de sus beneficios, si bien al tipo reducido del 25 por 100 -art. 28.2. a) del R.D. Legislativo 4/2004-, ventaja última que ha desaparecido también por completo, a partir del periodo tributario de 2016, en virtud de lo dispuesto en el artículo 29 y de la disposición transitoria 34 . i), $1^{\circ}$ de la vigente Ley 27/2014, que establece el tipo general del impuesto en el 25 por 100 y suprime a partir del ejercicio fiscal indicado buena parte de los tipos bonificados hasta entonces subsistentes, al subsumirlos en el tipo general.

La evolución legislativa descrita supone en este caso una injustificada e inadmisible penalización o discriminación negativa de los sistemas de previsión de genuino carácter mutual respecto al modelo que representan los planes y fondo de pensiones, situación que, como ha podido apreciarse, ha ido agravándose

15 Todavía alguna sentencia relativamente reciente, como la STS de 8 de abril de 2011, en recurso de casación núm. 1587/2006 (ponente Sr. Martinez Mico), ha interpretado dicha exención conforme a su estricta literalidad, con el efecto expresado de privarla en la práctica de alcance efectivo alguno. 
paulatinamente con el transcurso del tiempo. Permítaseme que sobre este particular reproduzca literalmente lo que ya manifesté al respecto en el año 1996:

"A mi juicio, cualquier tratamiento que no pase por homologar la fiscalidad de Entidades de Previsión Social Voluntaria al régimen aplicable a los Planes y Fondos de Pensiones resulta manifiestamente discriminatorio. La Ley 8/1987, de 8 de junio, en su misma exposición de motivos, reconoce que "los Planes de Pensiones se configuran como Instituciones de previsión voluntaria y libre", a las que expresamente sitúa en la órbita del artículo 41 de la Constitución (único precepto constitucional citado en el preámbulo), donde se proclama que la asistencia y las prestaciones complementarias al régimen público de la Seguridad Social serán libres.

Pese a este propósito de incorporar una fórmula más de previsión social que dinamizara el sector, la parte dispositiva del texto legal parece estar muy lejos de propiciar la coexistencia de los Planes y Fondos con las formas tradicionales de mutualismo. Como muestra, la disposición transitoria primera de la Ley 8/1987, en la que se advierte con claridad que la adecuación de las Entidades de Previsión Social a la nueva ordenación jurídica del sector pasa, a criterio del legislador, por su conversión en Fondos de Pensiones, esto es, por su desaparición pura y simple.

Así pues, la potenciación de los Fondos, como nuevo instrumento de previsión, y panacea contra todos los males, se hace a costa de las entidades preexistentes, cuya desaparición se propicia de manera abierta. A este fin, el dispar tratamiento fiscal constituye un poderoso factor de disuasión...

Pese a todo, las expectativas depositadas en los Fondos de Pensiones no han llegado a colmarse, y las Entidades de Previsión siguen subsistiendo. Es obligado, por ello, reclamar un trato fiscal equitativo, y su gravamen también a tipo cero. No puede admitirse que el legislador discrimine tan solo por la forma de previsión elegida, pues, obviamente, ello vulnera el principio de capacidad consagrado en el artículo 31 de la Constitución, así como el de igualdad del artículo 14. Cabe preguntar, a tal fin, ¿qué diferente capacidad contributiva manifiestan las Entidades de Previsión Social, respecto a los Fondos de Pensiones, que justifique este flagrante trato desigual? Mientras no se razone sobradamente la diferencia, es a todas luces ilegítimo penalizar los mecanismos de previsión autogestionados por los propios socios o partícipes, respecto a los administrados o gestionados por entidades financieras. Además, si aquéllas -las Mutuas- no han sido en algún caso concreto fiables, no parece que la solvencia y el rigor de estos otros-los Bancos y demás entidades financieras- haya demostrado en ocasiones ser superior. Por tanto, tampoco cabe explicar la diferencia en las mayores garantías a los partícipes que una forma de previsión concede sobre la otra." (Rodrigo Ruiz, 1996).

Dos décadas después estas consideraciones, lamentablemente, mantienen aún plena vigencia. Sin embargo, esa misma perpetuación del status quo descrito fuerza a radicalizar el discurso, puesto que, tanto desde la perspectiva de los principios informadores de la tributación como desde criterios de elemental equidad, el enjuiciamiento de la situación, convertida ya en endémica, es inaceptable y sigue careciendo de explicación alguna. $\mathrm{O}$, mejor dicho, si la tiene, a extramuros del 
ordenamiento jurídico y del interés general; y se encuentra en el pleno sometimiento de los poderes públicos a los designios e intereses de la banca y de las grandes corporaciones financieras. Se ha entregado a los bancos la plena disposición de una ingente suma de dinero privado destinado a cubrir las contingencias propias de la previsión social, bajo el expeditivo cauce de situar a las mutualidades dedicadas a esa misma finalidad en una desventaja fiscal extrema que elimine cualquier posible atisbo de competencia por parte de éstas. Para la consecución de este indisimulado propósito, patente en la Ley 8/1987 de Planes y Fondos de Pensiones, cuya disposición transitoria primera apostó sin reparos par la disolución de las mutuas y su conversión en fondos de pensiones, la legislación tributaria ha servido de principal y poderoso instrumento ejecutor. Paradójica y contradictoriamente, el carácter mutual, en este caso, se convierte, de forma deliberada, en un factor negativo y perjudicial, que sirve para acuñar un régimen fiscal mucho más gravoso, puesto que el legislador ha apostado porque sean las entidades crediticias, y no los propios ahorradores -a través de formatos mutualistas- los que administren sus aportaciones a la previsión social, entregándoles así en bandeja de plata el sector.

Como era de esperar, en un mundo financiero tan convulso y en el que han proliferado por doquier las prácticas irregulares y fraudulentas, no siempre las entidades gestoras de los Fondos han respondido a las expectativas y a la confianza depositadas en ellas, lo que ha conducido a que tanto la rentabilidad como la solvencia de esos Fondos haya sido en no pocas ocasiones muy distante de la que cabía esperar, llegando incluso a veces a constatarse que los intereses estratégicos o de ubicación en determinados mercados de las entidades gestoras han prevalecido sobre las conveniencias de los partícipes a la hora de planificar y ejecutar las inversiones. Al tiempo, existen vivas muestras del buen hacer que ha presidido el funcionamiento de experiencias mutualistas ${ }^{16}$, que han obtenido resultados notables aún en tiempos de crisis, en demostración de que en modo alguno es posible sostener la inferioridad de las fórmulas de signo mutual frente a las sociedades financieras de capital administradoras de Fondos, sino más bien todo lo contrario.

No resta sino reclamar la inmediata reparación del injustificable trato lesivo dispensado a las mutualidades de previsión social voluntaria, a la vez que se constata el opuesto y a todas luces contradictorio significado que se otorga según los casos al principio mutualista, que oscila desde ser el elemento que justifica la protección fiscal a las cooperativas y modula el nivel de la misma, a resultar un elemento inocuo que no produce efecto tributario apreciable alguno, como sucede con las sociedades laborales, para llegar a convertirse por último en un factor pernicioso que provoca en el ámbito de la previsión social una tributación muy superior a la que poseen en dicho segmento las sociedades financieras ajenas al mutualismo.

16 A título de simple ejemplo, valga citar a la Mutualidad de la Abogacía, a la Mutua Divina Pastora o a la EPSV Lagun Aro, por mencionar algunas entidades concretas que avalan dicho aserto. 


\section{Propuestas de reforma. Especial referencia al establecimiento en el impuesto de Sociedades de un tipo bonificado común aplicable a la mayoría de las entidades de la economía social.}

Las consideraciones precedentes muestran con toda nitidez las debilidades e imperfecciones de la normativa tributaria dictada para las diferentes entidades que forman parte de la economía social, y justifican la necesidad de un radical cambio de rumbo. Si algo ha quedado plenamente demostrado es que la situación actual, analizada bajo el prisma de los principios rectores del ordenamiento tributario y en base a postulados de mera coherencia y armonía legislativa interna, resulta completamente insostenible. La inconcebible disparidad de los diversos regímenes particulares existentes, sustentados en criterios no solo diversos, sino, tal como se ha comprobado, muchas veces abiertamente antagónicos e incompatibles entre sí, demanda de modo inaplazable una reforma que, a la vista de la experiencia pasada, solo puede abordarse a partir de una visión global y de conjunto que abarque y se extienda a cualquier tipo de entidad perteneciente a la economía social.

Esta necesaria modificación, en efecto, carece de viabilidad si se emprende de forma fraccionada, otorgando un tratamiento individualizado a cada sector específico que en un momento dado se halle en vías de transformación. Los antecedentes normativos revelan que la decantación y goteo sucesivos, en fechas distantes, de disposiciones aisladas dedicadas a establecer el régimen fiscal particular de un concreto segmento de la economía social, ha dado lugar a regulaciones de enfoque estrecho, cortas de mira y sin perspectiva global alguna. Incluso en estos momentos, con la ley de Economía Social en vigor (aunque en el más completo olvido por parte de los poderes públicos, como ya ha sido denunciado y la situación que pasa a describirse confirma tozudamente una vez más), la reciente reforma de la Ley de Sociedades Laborales ha incurrido en ese mismo error de partida, lo que provoca que se mantenga, sin más variación apreciable que la supresión de algunas bonificaciones, el planteamiento normativo preexistente ${ }^{17}$, de manera que se ha perdido una magnífica oportunidad para mejorar el tratamiento fiscal de estas sociedades y homologarlo o aproximarlo al de otros sectores de economía social, y patentiza que por la vía de la legislación singular no cabe esperar soluciones a la inaceptable disparidad legal existente.

Obviamente, la regulación tributaria común que se propugna no puede, habida cuenta las diferencias estructurales, jurídicas y de fines y objetivos entre las distintas entidades, alcanzar la uniformidad completa. Entre otras razones, porque no cabe prescindir de las reglas técnicas o de ajuste particulares que, como sucede por ejemplo en las cooperativas, se requieren en ocasiones para llevar a cabo la necesaria adaptación de las normas fiscales a la legislación societaria o sustantiva. Es por ello que ese tratamiento homólogo deberá limitarse al establecimiento de un mínimo común denominador, de unas previsiones básicas que puedan generalizarse a todo el ámbito de la economía social, sin perjuicio -se insiste- de aquellas normas específicas que en algún subsector sean precisas.

A mi juicio, la estipulación más trascendente que cabe propugnar de manera viable para el conjunto de las entidades de la economía social es la fijación de un

17 Vid. lo indicado al respecto en la anterior nota núm. 5. 
mismo tipo de gravamen bonificado en el impuesto de Sociedades aplicable a todas ellas -a reserva no obstante de las excepciones que luego se dirán-. Dicho tipo reducido, frente al general del 25 por 100 vigente (art. 29.1 de la Ley 27/2014, con efectos para los ejercicios que se inicien después de 2015 -disp. transitoria $34^{\mathrm{a}}, \mathrm{i}$-), debería situarse, para tener una efectiva función incentivadora, en torno al 15 por 100 , y en ningún caso tendría que rebasar con amplitud dicha cifra, pues de otro modo cobraría un significado casi testimonial de impacto insuficiente. El tipo de gravamen, además, ha de ser único y extender su aplicación a toda suerte de resultados que integren la base liquidable, suprimiéndose en todos los casos, y en particular en las cooperativas, la fragmentación o desdoblamiento de la base imponible y la actual sujeción de cada parte a diferente tipo de gravamen, medida que contribuiría de manera muy notable a facilitar la aplicación del impuesto y superar las altas dosis de presión fiscal indirecta, y de complejidad y correlativa inseguridad jurídica que la situación presente genera.

A fin de que el tipo único bonificado adquiera auténtico carácter general para todo tipo de entidad perteneciente a la economía social es necesario también que se supriman la mayor parte de los requisitos - por no decir todos - que se exigen hoy en día para el disfrute de los incentivos vigentes. La acumulación y variedad de estos requisitos hacen muchas veces inviables y de muy escasa utilidad las ventajas ofrecidas, ante el cúmulo de deberes y cargas que en contrapartida se imponen, extendiendo cada vez más la anómala práctica de renunciar voluntariamente a su aplicación, impropia de un ámbito imperativo como el tributario, donde tanto la obligación principal de contribuir como sus elementos esenciales son de configuración legal. Esta multiplicidad de condicionantes se sustenta en una enfermiza desconfianza patológica, tanto del legislador como de la Administración tributaria, que conduce a poner en duda apriorística y generalizadamente la buena fe de los destinatarios de la norma, y constituye un inadmisible prejuicio que, además, resulta ineficiente en grado superlativo: por un lado, la Administración carece de capacidad real y de medios para someter a control y verificar el efectivo cumplimiento del interminable y agotador catálogo de requisitos impuestos, lo que a la postre conduce en la práctica a que puedan llegar a disfrutar de los beneficios sin ulteriores problemas entidades que no respetan las prescripciones legales, con las irregularidades y distorsiones de toda índole que ello acarrea; por otro, los entes que pretenden cumplir rigurosamente la normativa se encuentran con frecuencia en una situación de incertidumbre elevada, a causa de las diferentes interpretaciones y lecturas que muchas veces pueden hacerse respecto al alcance y significado final de tales requisitos, añadiéndose también a la inseguridad jurídica que la complejidad normativa acarrea, con su carga de mayor conflictividad, una presión fiscal indirecta elevada, propiciada en este caso por el intenso esfuerzo de control interno que la regulación impone a fin de no infringir ni rebasar ninguno de los múltiples límites establecidos ${ }^{18}$.

La supresión de esa multiplicidad de requisitos implica que, por regla general, debería ser suficiente, para aplicar el tipo bonificado, con cumplir la legislación

18 Una muestra de las funestas consecuencias que ocasiona el incumplimiento de alguno de esos múltiples y complejos requisitos, con perdida incluso del derecho a aplicar el régimen tributario especial, puede verse en las SSTS de 18 y 20 de diciembre de 2013, en recursos de casación núms. 4885/2011 y 2943/2010 -ponentes Sres. Garzón Herrero y Huelin Martinez de Velasco, respectivamente-. 
societaria y las exigencias sustantivas que la constitución y funcionamiento de cada entidad demanda con arreglo a su normativa propia. En principio, siempre que se respeten las reglas que permiten, conforme a su respectiva legislación específica, calificar a la entidad dentro de un segmento perteneciente a la economía social (cooperativas, sociedades laborales, mutualidades, etc), reglas que ya son per se suficientemente exigentes, el tipo bonificado resultará aplicable, y solo por vía de excepción cabría en algún caso singular y extremo añadir algún requisito adicional, cuando éste se encontrase plenamente justificado conforme al principio de capacidad económica o cualquier otro principio constitucional de naturaleza tributaria.

Algunas figuras de la economía social, sin embargo, deberían disponer todavía de un nivel superior de protección fiscal. En concreto, habrían de ser declaradas íntegramente exentas del impuesto de Sociedades la fundaciones y asociaciones de utilidad pública comprendidas en la Ley 49/2002, y también cualquier otra entidad de economía social que, dedicándose efectivamente de modo exclusivo o significativamente mayoritario a la cobertura y atención de fines de interés público o general, tenga vetada además, por mandato legal o prohibición estatutaria, tanto la distribución de beneficios como el reparto y adjudicación del patrimonio social entre los socios, miembros o participes, incluso en el caso de disolución de la entidad. Carece de sentido detraer por vía impositiva parte de los beneficios de una entidad, a fin de allegar ingresos para la cobertura de los gastos públicos, cuando la totalidad de las actividades y fondos de dicho ente están ya destinados a fines públicos, motivo que justifica la exención absoluta preconizada. Como mucho, podría fijarse un gravamen simbólico, con miras más a la ordenación y racionalización de esas loables iniciativas privadas -lo que tampoco parece que deba hacerse por vía fiscal-, que con propósito verdaderamente recaudatorio.

Y, por último, resulta ocioso añadir, tras las consideraciones vertidas respecto a las mutualidades de previsión social, que para ellas ha de establecerse sin dilación un régimen de tributación a tipo cero en el impuesto de Sociedades, es decir, de exención total, al igual que sucede desde hace casi dos décadas con los planes y fondos de pensiones, por un elemental imperativo de equidad y no discriminación ${ }^{19}$. La situación actual es intolerable y supone un flagrante quebranto del principio constitucional de igualdad establecido en los artículos 14 y 31 de la Constitución (precepto éste último que preconiza un sistema tributario justo basado en la igualdad): quebranto que tiene ya todos los visos de convertirse en endémico -lo que, lejos de restar gravedad a la violación constitucional denunciada, sin duda la incrementa al perpetuar sine die la infracción-.

De otra parte, el resto de las ventajas fiscales establecidas por algunas variedades de la economía social por su régimen tributario específico deberían también uniformarse y extenderse a toda suerte de entidades pertenecientes al sector. Aunque la mayoría de dichas ventajas -libertad de amortización en el impuesto de Sociedades, exención en el ITP y AJD para la transmisión onerosa de determinados bienes y para la constitución y transformación de sociedades,

19 Coincide con esta apreciación Fuster Asensio, C. (2009: 179), quien afirma al respecto: "Las MPS deben gozar de un tratamiento fiscal incentivador que las equipare en cuanto a la fiscalidad con los planes y fondos de pensiones. Nada justifica, dado que ambos son sistemas complementarios del sistema público de la Seguridad Social, una diferencia de trato, favorecedora para estos últimos, desde un punto de vista fiscal". 
exención o bonificación en el IAE- ha perdido buena parte de su significado inicial, bien por haberse extendido a una gran variedad de supuestos que hacen perder a la regla su carácter singular o especial, bien por haber limitado significativamente su incidencia, como pasa con la exención a las transmisiones inmobiliarias en el ITP a partir de la ya lejana entrada en vigor del IVA, dicha merma de significación no puede servir de excusa para justificar la disparidad normativa existente. Por tanto, también en el ámbito de la imposición estatal indirecta -en particular, en el ITP y AJD- y en el de la tributación local ha de tenderse a establecer una regulación común que otorgue, en lo básico, el mismo tratamiento a todas las entidades de la economía social, porque la variedad actual carece de nuevo de explicación solvente.

Las medidas propuestas tienen todas ellas, y muy en particular la consistente en el establecimiento de un tipo bonificado común en el impuesto de Sociedades, la doble virtud de que su implantación es muy sencilla y además resulta plenamente viable, tanto en el plano jurídico como en cuanto a su eventual impacto recaudatorio. Para las sociedades cooperativas, ese tipo único reportaría significativas ventajas. En primer lugar, permite recuperar parte de la merma de protección fiscal que comparativamente han sufrido las cooperativas en relación a las sociedades sujetas a tipo general desde la aprobación de la Ley 20/1990, momento aquél en que entre el tipo bonificado para los resultados cooperativos (tipo del 20 por 100 que a fecha de hoy no ha experimentado variación alguna) y el tipo general (del 35 por 100) existía un diferencial de 15 puntos, frente a los escasos 5 puntos de distancia que se ha establecido a partir del año 2016 con arreglo a la legislación ahora vigente. En segundo lugar, el tipo único evita también el fraccionamiento de la base imponible que hoy se requiere para realizar el necesario desglose tributario de los resultados cooperativos, por un lado, y los extracooperativos, por otro, extremo sobre el que me he pronunciado críticamente desde antes de su implantación legal (Rodrigo Ruiz, 1989), y que genera nuevamente un alto grado de incertidumbre e inseguridad y una exagerada presión fiscal indirecta. En tercer y último lugar, haría desaparecer la artificial distinción entre cooperativas protegidas y especialmente protegidas -salvo que quisiera mantenerse para las segundas alguna bonificación en la cuota, o cualquier otra norma semejante a la que contempla el art. 34.2 de la Ley 20/1990 (previsión que a mi juicio debiera eliminarse si se establece el tipo reducido común propuesto)-; la supresión de esa dualidad de trato fiscal entre unas cooperativas y otras, carente hoy en día de razones sólidas que la justifiquen, eliminaría de raíz, obvio es decirlo, los múltiples problemas y la disparidad que dicha dicotomía legal suscita en la práctica. En consecuencia, la simplificación que la implantación de un tipo único reducido reporta en el ámbito de las cooperativas es evidente y significativa, sin merma apreciable alguna, además, ni de los principios de justicia tributaria, ni tampoco de los incentivos fiscales vigentes ahora para dicho segmento de la economía social.

A su vez, las sociedades laborales encontrarían en la tributación a tipo reducido en el impuesto de Sociedades el nivel de protección fiscal razonable, equilibrado y sencillo que vienen justamente demandando. Únicamente cabría exigir que se mantenga en un porcentaje mínimo el carácter mutual del trabajo realizado, para que la participación laboral de los socios trabajadores en el conjunto de la actividad 
de la empresa no termine siendo residual o poco significativa; dicho requisito fiscal añadido podría introducirse en el caso de que, como porfía el sector, fuera desfigurada en exceso esta nota distintiva de las sociedades laborales en la legislación sustantiva ${ }^{20}$.

En cuanto a las entidades parcialmente exentas pertenecientes a la economía social que se mencionan en el artículo 9.3 de la Ley 27/2014 del impuesto de Sociedades (entidades a las que es de aplicación el régimen especial establecido en los arts. 109 a 111 de dicho texto legal), la fijación del tipo único bonificado, incluso si fuera acompañado de la supresión de la exención parcial que en la actualidad disfrutan, ha de resultar en la mayoría de los casos claramente favorable. Repárese en que la exención no alcanza a ningún tipo de actividad económica que realicen tales entidades, de manera que en cuanto sus ingresos dominantes procedan de actividades de esa índole, o incluso de cuotas de sus asociados o colaboradores que otorguen derecho a percibir una prestación que sea consecuencia de una actividad económica, el régimen fiscal establecido reporta una reducción de la carga tributaria de muy escasa dimensión (hasta el punto de convertir en ocasiones el régimen especial en perjudicial y contraproducente). Así las cosas se antoja difícil que las Mutuas colaboradoras de la Seguridad Social, que realizan actividades de signo inequívocamente económico, o las uniones, federaciones y confederaciones de cooperativas, que además de su función representativa tienden también a prestar servicios a sus asociadas que en la mayor parte de las ocasiones se hallarán vinculados a una actividad económica, vayan a encontrar en el vigente régimen especial un incentivo tributario de relieve. Por tanto, solo las entidades sin fines de lucro incluidas en este concreto régimen de entidades parcialmente exentas (esto es, aquellas no acogidas a la Ley 49/2002) pueden obtener del régimen vigente de exención parcial una utilidad mayor. Pero para lograr un efecto real más favorable será preciso que esas fundaciones y asociaciones no realicen ninguna actividad económica -supuesto que, a tenor de lo previsto en el artículo 5.1 de la Ley de Economía Social 5/2011, deja fuera del sector de la economía social a dicho ente, por lo que la situación se halla al margen del ámbito al que se circunscribe el presente estudio- o que desempeñen una actividad económica residual, que tenga muy escasa incidencia respecto a la cifra global de ingresos.

Finalmente, para el resto de las entidades nominalmente incluidas por la Ley 5/2011 en la economía social, su carencia de regulación tributaria especifica convierte evidentemente en ventajoso el tratamiento fiscal propugnado, y eliminaría también las distorsiones y diferencias que se producen en tales entes empresas de inserción, centros especiales de empleo, etc.- según la forma jurídica adoptada (resaltan la diferente fiscalidad de estas entidades en el impuesto de Sociedades en función de la forma jurídica adoptada, Calvo Vergez, 2005 y Bonet Sánchez, 2010).

20 La Ley 44/2015 amplia sustancialmente el número de horas-año que pueden trabajar los trabajadores no socios contratados por tiempo indefinido para que la sociedad tenga la calificación de laboral, margen que, ha pasado de un máximo del 15 por 100 del total de horas-año trabajadas por los trabajadores socios (art. 1.2 de la Ley 4/1997) al 49 por 100 de las mismas (art. 1.2, c de la nueva ley). Aunque el porcentaje es suficiente en principio para respetar el significado mutual, nada se dice respecto a los trabajadores con contrato temporal, lo que, a la vista del actual mercado de trabajo, de la legislación laboral vigente, y de las prácticas que genera, puede dar lugar a abusos en que la participación efectiva en el trabajo de los socios termine siendo muy reducida. 
La viabilidad de las medidas propuestas se demuestra a su vez ante la constatación, en modo alguno baladí, de que los ordenamientos tributarios forales del País Vasco ya cuentan con disposiciones que establecen un tipo único para el gravamen de todos los beneficios de las sociedades cooperativas, cualquiera que sea su procedencia (aunque persiste la distinción entre las cooperativas protegidas y las especialmente protegidas $^{21}$ ), y mantienen también desde $1988^{22}$ la sujeción a tipo cero en el impuesto de Sociedades para las entidades de previsión social voluntaria $^{23}$. Se aprecia por tanto, aunque sea de manera sin duda incipiente, que los regímenes concertados han dado alguna muestra de avanzar en la línea señalada, si bien resta aún un largo trecho para alcanzar un tratamiento homogéneo de la economía social en su vertiente tributaria. A mi entender, huelga decirlo, sería altamente deseable que dicho camino pendiente se recorriera sin demora.

Descritas las líneas maestras del régimen tributario común que para las entidades de la economía social se propugna, y expuesto también el impacto que la medida acarrearía para cada tipo de entidad, es necesario, por último, precisar o concretar las razones que justifican su implantación. Entiendo, a este propósito, que el fundamento en que se asienta dicho régimen, y que otorga plena justificación al mismo, se encuentra en la adecuada protección y fomento del conjunto o pluralidad de principios y valores que constituyen el sello distintivo de la economía social y de las entidades que pertenecen a ese sector. Ciertamente, algunos de estos principios operan con mayor o menor intensidad según los casos, dependiendo del tipo de entidad de la economía social de que se trate, dada la amplia diversidad de modalidades existente, pero por encima de estas diferencias hay un factor dominante que aglutina e identifica a todas ellas: su pertenencia a una categoría jurídica unitaria - la de las entidades de la economía social-, que se distingue

21 En cuanto al tipo unificado de las cooperativas, vid. los arts. 26.2 de la Norma Foral de Guipúzcoa 2/1997, de 22 de mayo, sobre Régimen fiscal de las cooperativas; 26.2 de la Norma Foral de Álava 16/1997, de 9 de junio; y 25.2 de la Norma Foral de Vizcaya 9/1997, de 14 de octubre, preceptos mediante los que se introdujo dicha medida.

22 Art. 4 de la Norma Foral de Vizcaya 6/1988, de 30 de junio; art. 4 de la Norma Foral de Guipúzcoa 7/1988, de 15 de julio y art. 4 de la Norma Foral de Álava 24/1988, de 18 de julio.

23 Conviene advertir que en cuanto los Territorios forales del País Vasco aprobaron esa regulación fiscal para las entidades de previsión social voluntaria (EPSV), en paridad con la de los planes y fondos de pensiones, todos los bancos y entidades de crédito de relieve presentes en dicha Comunidad Autónoma, que por supuesto gestionaba y administraban ya sus propios y numerosos planes y fondos de pensiones, se lanzaron de inmediato a crear también, con domicilio social en esa autonomía, entidades de previsión social vinculadas al respectivo banco o sociedad crediticia, en un forzado intento de seguir monopolizando hasta el máximo posible el sector de la previsión social complementaria. Muchas de estas EPSV de iniciativa bancaria no cumplen ni por asomo los principios y reglas de funcionamiento propias del mutualismo, sino que son gestionadas como si fuesen otro fondo de pensiones más, de manera que una comprobación tributaria sobre dicho extremo debiera conducir a la descalificación de la entidad y a la correlativa perdida del derecho a la aplicación del régimen fiscal singular, demostrando la utilidad que tienen las reglas contenidas en la legislación sustantiva como requisito bastante cuyo cumplimiento ha de facultar por sí mismo, sin necesidad de aderezos ni añadidos, para disfrutar de los incentivos fiscales estipulados en favor de las entidades de economía social. Con todo, la sujeción estricta al principio de realidad obliga a advertir que la inspección tributaria a estas ficticias entidades de previsión auspiciadas por la banca -como la que demandan a gritos las sociedades de inversión de capital variable (SICAV) en cuanto al auténtico cumplimiento del número mínimo de socios exigible en dichas sociedades- ni se ha producido hasta ahora ni se le espera, lo que patentiza una vez más que también en el terreno de la aplicación administrativa de las normas tributarias los criterios de igualdad e imparcialidad, y por ende el de mera eficiencia en la corrección de situaciones tan palmarias y relevantes, brillan escandalosamente por su ausencia. 
precisamente (art. 4 de la Ley 5/2011) por la concurrencia en todas las ocasiones de unos mismos principios orientadores. Es por tanto la globalidad de estos principios, y no la simple presencia o la preponderancia de alguno de ellos en particular, lo que caracteriza a la economía social y justifica un régimen tributario común para todas sus piezas integrantes (en esta línea, Calvo Ortega, 2005; y Rodrigo Ruiz, 1985). El respeto a dichos valores y el cumplimiento de los principios constitutivos de la economía social ha de bastar, en consecuencia, para que un determinado ente pueda acogerse al régimen fiscal señalado, y tal presupuesto debe considerarse alcanzado con la simple, aunque escrupulosa, observancia de las normas que regulan la creación y funcionamiento de cada clase de entidad, ya de por sí suficientemente rigurosas en orden a preservar que dichos principios no se infringen. Un funcionamiento de la entidad acorde con la normativa sustantiva que la regula significa que ésta cumple con los criterios y principios informadores de la misma, y ha de ser requisito suficiente para acceder al régimen tributario especial establecido en protección y fomento de tales principios.

Fundamentar el régimen fiscal singular para toda la economía social en el catálogo completo de principios que identifican y distinguen a las entidades del sector tiene dos importantes consecuencias, que sí bien se deducen con nitidez de cuanto acaba de indicarse, no está de más que sean debidamente explicitadas. Conforme a la primera, puede decirse que no resulta apropiado focalizar la atención, tal como se ha hecho hasta el presente, cara a la fijación y disfrute de incentivos fiscales, en algún aspecto singular y aislado, por importante que sea, de entre los que concurren en las entidades del sector. Con esa concepción de priorizar unos principios sobre otros, o de hacer que los beneficios tributarios dependan de un solo principio concreto (sea el mutualista o cualquier otro), se consigue el resultado perverso de que caigan en el olvido, cuando no en el más absoluto desprecio, todos los restantes principios informadores de la economía social, igualmente susceptibles de justificar un tratamiento fiscal ventajoso. Además, ese enfoque impide una visión global del sector y de la pluralidad de valores en que se asienta, y conduce a establecer diferencias artificiosas e inapropiadas entre las diversas clases de entes que forman parte de ese ámbito económico, en función del modo en que el concreto principio elegido para sustentar la protección fiscal se hace presente en cada una de ellas, y de la intensidad de dicha presencia. La segunda consecuencia sirve para recalcar que, como ya se ha apuntado, para acogerse y poder aplicar el régimen tributario propuesto ha de resultar suficiente con el adecuado respeto a la legislación sustantiva que regula cada tipo de entidad, sin introducirse exigencias añadidas o complementarias de ninguna clase, puesto que es la mera y simple pertenencia a la economía social, y el cumplimiento de su normativa sectorial, la circunstancia que habilita por sí sola a acceder al tratamiento tributario especial propugnado. Desde esta perspectiva, la introducción de requisitos adicionales resulta lesiva para la promoción integral de toda la economía social en su conjunto y puede tener efectos discriminatorios entre sus distintas piezas integrantes.

La apelación a la globalidad de los principios y rasgos caracterizadores de la economía social en orden a dar cobertura a un régimen tributario común específico para el sector cuenta, por descontado, con pleno refrendo legal. Ya el preámbulo de la ley 5/2011 de Economía Social hace mención a "un conjunto de principios que 
permiten plasmar una realidad diferenciada de las entidades de la economía social, tales como la primacía de la persona y del objeto social sobre el capital, la adhesión voluntaria y abierta, el control democrático por sus integrantes, conjunción de los intereses de las personas usuarias y del interés general, defensa y aplicación de los principios de solidaridad y responsabilidad, autonomía de gestión e independencia respecto de los poderes públicos y el destino de los excedentes a la consecución de objetivos a favor del desarrollo sostenible, del interés de los servicios a sus integrantes y del interés social". Además, las notas distintivas que acaban de reproducirse trascienden del mero preámbulo $\mathrm{y}$, como ya se ha dicho, han encontrado acomodo también en el artículo 4 del propio texto legal, precepto en el que se describen con mayor detalle y amplitud dichos elementos caracterizadores, que reciben del legislador el calificativo de "principios orientadores" de las entidades de la economía social.

Por tanto, la Ley de Economía Social, en su declarado propósito de perfilar dicho sector y otorgarle reconocimiento singular, bajo la consideración de actividad diferenciada a la que se pretende dotar de un marco jurídico común, construye la identidad de la categoría jurídica objeto de ordenación en base, precisamente, a la presencia simultánea y coincidente de unos mismos principios de actuación (así se desprende de una lectura conjunta de los artículos 1, 2 y 4 del texto legal). Habida cuenta de que esa conjunción de principios ha de presidir y estar ineludiblemente presente en la creación y funcionamiento del amplio elenco de entidades que se adscriben al ámbito de la economía social, todas ellas, sin excepción, se hacen acreedoras a un régimen común de protección e incentivación fiscal, superando así los particularismos que han dado lugar a la actual proliferación de normativas tributarias singulares para los distintos segmentos de la economía social.

Resultaría ocioso decir, si no fuera en razón a pasadas experiencias, que la regulación tributaria que se defiende debe superar sin problemas cualquier examen que pudiera suscitarse desde el prisma del Derecho comunitario, tanto si se realiza en virtud de la prohibición de ayudas de Estado o en defensa de cualquier libertad fundamental, como si se plantea en base a cualquier otro mandato comunitario (se refieren a los problemas de orden comunitario que ha suscitado la fiscalidad de las cooperativas, mutuas y otras formas de economía social, Alguacil Marí, 2010; Arana Landín, 2012; Bahía Almansa, 2011; y Merino Jara, 2010). De un lado, el régimen fiscal bonificado no se vincula ya a personas jurídicas de una naturaleza o tipología societaria concreta, de manera que difícilmente pueden considerarse selectivas desde esta perspectiva; de otro, las exenciones y bonificaciones se vinculan a la promoción y defensa de un amplio conjunto de principios y valores que, al menos nominalmente, son también acreedores de especial protección y de atención preferente conforme al Derecho de la Unión europea y a las reiteradas declaraciones de reconocimiento y apoyo pronunciadas por todas las Instituciones comunitarias $^{24}$.

24 Entre otros pronunciamientos, cabe citar el Informe 2008/2250 (INI) de 26 de enero de 2009 surgido en el Parlamento Europeo; la Comunicación de la Comisión (Doc. COM/2004/18 final) de 23 de febrero de 2004 al Consejo, al Parlamento Europeo, al Comité Económico y Social Europeo y al Comité de Regiones sobre fomento de las cooperativas en Europa (comunicación que sin embargo resulta en algunos aspectos muy reticente); los dictámenes del Comité Económico y Social Europeo sobre Economía Social y mercado único 
Desde una óptica de técnica legislativa, y cara a evitar los señalados reparos comunitarios, ya he apuntado en una anterior oportunidad (Rodrigo Ruiz, 2010: 2023) que da toda la impresión, en base a las propias categorías que utiliza la Comisión europea, de que el establecimiento de tipos reducidos con respecto al general, aplicables sin excepción al conjunto de los resultados obtenidos, suscita menores resistencias en orden a reconocer su compatibilidad con el ordenamiento comunitario, siempre que, como es el caso, exista justificación para establecer un régimen particular. Es en consecuencia a través de esta vía por la que habría de discurrir una futura reforma de la legislación española. La multiplicidad de tipos de gravamen existentes dentro del impuesto de Sociedades en prácticamente todos los estados miembros, y la gran disparidad de tipos nominales existentes entre unos países y otros hace muy difícil a la Comisión cuestionar situaciones aisladas con olvido de todas las demás, por lo que en lugar de implantar reglas de atenuación en otros elementos del tributo -base imponible, cuota- es más conveniente situarlas en el tipo de gravamen.

En esta misma línea, cabe también precisar que, si bien una bonificación en la cuota o la minoración del tipo para una sola parte de los beneficios, como sucede en el régimen tributario de las cooperativas, permite conseguir mermas en la carga fiscal iguales o superiores a las que se logren con la fijación de un tipo único rebajado respecto al ordinario o general del impuesto, pueden detectarse ciertas diferencias entre esas variadas fórmulas. Por de pronto, la coincidencia de dos tipos de gravamen diversos, cada uno para una fracción del beneficio, así como la exclusión de la mitad de la cuota resultante (casos ambos que se dan nuevamente en las cooperativas), patentizan de manera muy evidente o visible que se está dispensando a la entidad beneficiaria un trato manifiesto de favor, por muy razonable que sea la medida. Constituyen previsiones legislativas cuya singularidad se aprecia de inmediato, de forma directa, sin necesidad de acudir a la comparación con el régimen general del tributo. En cambio, el establecimiento de un tipo impositivo específico para el conjunto de los resultados, aunque sea distinto e inferior al que se aplica a otras sociedades, tiene otras connotaciones, pues puede revelar simplemente que la capacidad contributiva de unos y otros sujetos no es la misma. De cumplirse esta premisa -la existencia de diferentes niveles de capacidad, lo que sucede en todos los entes cuyos excedentes, activos o patrimonio fundacional son total o parcialmente irrepartibles-, la concreción en cada caso del tipo de gravamen correspondiente es una decisión libérrima (aunque dentro de unos límites razonables) del legislador, es un asunto de política fisca ${ }^{25}$ donde los estados disponen de un alto grado de discrecionalidad (más aun mientras no se logre armonizar la imposición directa), de manera que, como acaba de indicarse, el

(año 2000), y sobre "Distintos tipos de empresa", de 1 de octubre de 2009. Este último Dictamen del Comité Económico y Social Europeo señala en sus apartados 1.12 (sobre conclusiones y recomendaciones) y 4.5.1 (sobre Derecho fiscal) que "el CESE pide a la Comisión que anime a los Estados miembros a que estudien la posibilidad de conceder medidas compensatorias a las empresas sobre la base de su utilidad pública comprobada o de su contribución constatada al desarrollo regional".

$25 \mathrm{Ni}$ siquiera en aquellos impuestos armonizados, como el IVA, los tipos de gravamen aprobados por los estados miembros han de ser coincidentes, como tampoco el ámbito de aplicación de los tipos reducidos tiene que coincidir con exactitud. 
cuestionamiento por la Comisión europea de una medida de esta naturaleza es asunto altamente complejo.

\section{Conclusiones}

Las consideraciones que anteceden permiten formular las conclusiones siguientes:

1.- Desde una perspectiva de conjunto, la situación tributaria actual de la economía social, plagada de regímenes fiscales singulares de variopinto y dispar contenido, no es en modo alguno aceptable. Motivos de racionalidad, de armonización y congruencia normativa, de equidad elemental y de respeto a los principios rectores de la imposición reclaman inaplazablemente una modificación sustancial del presente estado de cosas.

2.- No resulta tampoco de recibo que la protección se centre, prácticamente en exclusiva -con la sola excepción de las entidades sin fines lucrativos (fundaciones y asociaciones) de la ley 49/2002-, en la presencia del criterio o principio mutualista, con abandono y olvido de los demás principios y valores informadores de las entidades de economía social, y más criticable es todavía que dicho factor mutual genere efectos diversos e incluso radicalmente antagónicos, hasta el punto de convertirse en el elemento nocivo causante de un trato tributario perjudicial en el caso de las mutualidades de previsión social.

3.- Existen razones solidas bastantes para propugnar un régimen tributario común para todas las entidades de la economía social, que a mi entender ha de asentarse en dos medidas básicas:

3.1. establecimiento, como incentivo prioritario, de un tipo bonificado único en el impuesto de Sociedades, que debería situarse al menos en el 15 por 100 o, en el peor de los casos, muy poco por encima de dicha cota, cuya aplicación ha de extenderse a todos los segmentos de la economía social, con dos únicas salvedades que en la conclusión siguiente se precisarán.

3.2. fijación de un catálogo unitario de exenciones y bonificaciones en la imposición estatal indirecta (especialmente en el ITP y AJD) y en los tributos locales, que puede completarse no obstante con alguna medida aislada, en favor de algún grupo concreto de la economía social, cuando exista justificación suficiente para dicha regla especifica.

4.- La tributación en el impuesto de Sociedades con arreglo al tipo reducido señalado en la anterior conclusión ha de contar con dos excepciones, sobradamente fundadas, referidas a:

4.1. las fundaciones y asociaciones de utilidad pública comprendidas en la ley 49/2002, y también a cualquier otra entidad de economía social que, dedicándose efectivamente de modo exclusivo o significativamente mayoritario a la cobertura y atención de fines de interés público o general, tenga vetada además, por mandato legal o prohibición estatutaria, tanto la distribución de beneficios como el reparto y adjudicación del patrimonio social entre los socios, miembros o participes, incluso en el caso de disolución de la entidad, supuestos todos ellos en los que debiera establecerse una exención completa de la totalidad de los beneficios en el impuesto de Sociedades. 
4.2. las mutualidades de previsión social, a las que ha de concederse el gravamen a tipo cero en el impuesto de Sociedades, en justa y obligada equiparación con el régimen fiscal de los planes y fondos de pensiones.

5.- Las medidas propuestas encuentran renovado apoyo en la ley de Economía Social 5/2011, amén de tener sustento en principios y valores protegidos constitucionalmente de sobras conocidos, a los que la doctrina ha apelado con reiteración desde hace tiempo. Al propio tiempo, lejos de entrar en colisión con el ordenamiento comunitario, tales medidas cuentan en su haber con el respaldo explícito que las Instituciones europeas han prestado a las distintas formas de economía social en repetidas ocasiones, y con las apelaciones al fomento de las mismas que tales Instituciones expresan.

\section{Referencias bibliográficas}

Alguacil, M.P. (2010) Condicionantes del régimen de ayudas de Estado en la fiscalidad de cooperativas. Ciriec-España, Revista de Economía pública, social y cooperativa, $\mathrm{N}^{\mathrm{o}} 69$, pp. 27 y ss.

Arana, S. (2012) Régimen fiscal de las cooperativas. Servicio Publicaciones UPV/EHU. Leioa (Bizkaia).

Bahia, M.B. (2011) El régimen fiscal especial de las cooperativas y su compatibilidad con la normativa sobre ayudas de Estado. Ciriec-España. Revista Jurídica de Economía Social y Cooperativa, $\mathrm{N}^{\circ} 22$, pp. 151 y ss.

Barberena, I. (1992) Sociedades cooperativas, anónimas, laborales y agrarias de transformación. Régimen fiscal. Ed. Aranzadi, Pamplona.

Bonet, M.P. (2010) Empresas de inserción: razones para una fiscalidad específica. CiriecEspaña. Revista Jurídica de Economía Social y Cooperativa, $\mathrm{N}^{\circ} 21$, pp. 87 y ss.

Calvo, R. (2005) Entidades de Economía social. Razones para una fiscalidad específica. Fiscalidad de las Entidades de Economía Social. Ed. Thomson/Civitas, Cizur Menor (Navarra), pp. 33 y ss.

Calvo, J. (2005) Centros especiales de empleo: marco normativo y régimen tributario. Fiscalidad de las entidades de economía social. Dir. CALVO, R. Thomson/Civitas, Cizur Menor (Navarra), pp. 528 y ss.

- Empresas de inserción social: delimitación jurídica y aspectos tributarios. Fiscalidad de las entidades de economía social. Dir. CALVO ORTEGA, R. Thomson/Civitas, Cizur Menor (Navarra), 2005, pp. 590 y ss.

Chaves, R.; Monzon, J.L.; Perez De Uralde, J.M. y Radrigan, M. (2013) La Economía Social en clave internacional. Cuantificación, reconocimiento institucional y visibilidad social en Europa, Iberoamérica y norte de África. REVESCO. Revista de Estudios Cooperativos, $\mathrm{N}^{\circ}$ 112, pp. 122-150. DOI: 10.5209/rev_REVE.2013.v112.43069.

De La Peña, G. (1997) Régimen tributario de las Sociedades Laborales, en AAVV, Régimen Jurídico de las Sociedades Laborales (Ley 4/1997). Tirant lo Blanch. Valencia.

De Luis Esteban, J.M. (1985) Presente y futuro de la fiscalidad de las cooperativas. Hacienda Pública Española, $\mathrm{N}^{\circ}$ 93, pp. 91 y ss.

Fajardo, G. (2011) La Ley española de Economía Social. Reformas legislativas en el Derecho Social y Solidario Iberoamericano. Fundibes y Fundación Divina Pastora. Valencia, pp. 35 y ss. 
Fuster, C. (2009) Razones que justifican una fiscalidad específica de las Mutualidades de Previsión Social. Ciriec España. Revista Jurídica de Economía Social y Cooperativa, $\mathrm{N}^{\mathrm{o}} 20$, pp. 149 y ss.

Garcia, Y. y Ruiz, M. (2005) Régimen tributario actual en el ordenamiento español. Fiscalidad de las Entidades de Economía social, Dir. CALVO ORTEGA, R. Thomson/Civitas, Cizur Menor (Navarra), pág. 73 y ss.

Mateo, L. (1989) Aspectos fundamentales de la fiscalidad de las cooperativas. Primeros encuentros cooperativos de la Universidad del País Vasco. Servicio Central de Publicaciones del Gobierno Vasco. Vitoria-Gasteiz, pp. 159 y ss.

Merino, I. (2010) El régimen fiscal de las cooperativas ¿respeta el régimen comunitario de ayudas de Estado?. REVES, Revista Vasca de Economía Social, No 6, pp. 29 y ss.

Montero, M. (2001) Análisis de los elementos esenciales del Régimen Tributario de las Sociedades Cooperativas. Crónica Tributaria, No 101, pp. 150 y ss.

Montesinos, S. (2012) Ley de Economía Social. Interés general y regímenes tributarios especiales. Ciriec-España. Revista Jurídica de Economía Social y Cooperativa, № 23, pp. 9 y ss.

Monzon, J.L. (Coord.); Calvo, R.; Chaves, R.; Fajardo, I.G. y Valdes, F. (2009) Informe para la elaboración de una Ley de fomento de la economía social. Ministerio de Trabajo. Madrid.

Paniagua, M. (2011) Las empresas de la economía social. Más allá del contenido de la Ley 5/2011, de Economía Social. Marcial Pons.

Paz, N. (2012) Comentario sistemático a la Ley 5/2011, de Economía Social. Tirant lo Blanch.

Perez, J.M. (2012) Algunas consideraciones sobre la repercusión de la Ley 5/2011, de 29 de marzo, de economía social en la Comunidad Autónoma de Euskadi. REVES, Revista Vasca de Economía Social, No 8, pp. 37 y ss.

- (2014) La inaplicación de la ley de Economía Social en un contexto de crisis económica. Algunas interpretaciones y propuestas. Ciriec-España. Revista de Economía pública, social y cooperativa, $\mathrm{N}^{\circ} 81$, pp. 33 y ss.

Rodrigo, M.A. (1989) Análisis crítico del Proyecto de Ley de Régimen Fiscal de las Cooperativas. Especial referencia a la tributación en el impuesto de Sociedades. El Régimen Fiscal de las Cooperativas. VII Jornadas de Cooperativas de Euskadi. Servicio Central de Publicaciones del Gobierno Vasco. Vitoria-Gasteiz, pp. 45 y ss.

- (1996) La fiscalidad de las entidades de previsión social en el impuesto de Sociedades. Crónica de una discriminación. Noticias de la Economía Pública, Social y Cooperativa CIDEC, $\mathrm{N}^{\mathrm{o}} 17$, pp. 47 y ss.

- (2003) Mandato constitucional de fomento y fiscalidad de las cooperativas. CiriecEspaña. Revista de Economía Pública, Social y Cooperativa, No 47, pag. 199 y ss.

- (2010) Consideraciones sobre el régimen fiscal de las cooperativas. Problemas actuales y líneas de reforma. Ciriec-España. Revista de Economía pública, social y cooperativa, $\mathrm{N}^{\mathrm{o}} 69$, pp. 9 y ss. 